Supporting Information

\title{
Protein Binding and Release by Polymeric Cell-Penetrating Peptide Mimics
}

Hazel C. Davis, ${ }^{\dagger}$ Nicholas D. Posey, ${ }^{\dagger}$ and Gregory N. Tew ${ }^{*}, \dagger, \sharp \S$

tDepartment of Polymer Science \& Engineering, University of Massachusetts, Amherst, Massachusetts 01003, United States

* Molecular and Cellular Biology Program, University of Massachusetts, Amherst, Massachusetts 01003, United States

§Department of Veterinary \& Animal Sciences, University of Massachusetts, Amherst, Massachusetts 01003, United States

*Email:tew@mail.pse.umass.edu 


\section{Table of Contents}

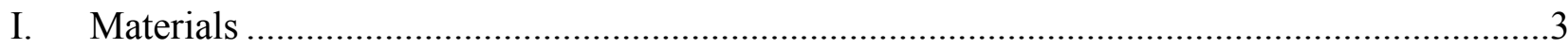

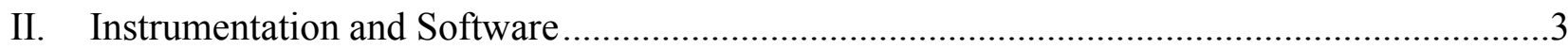

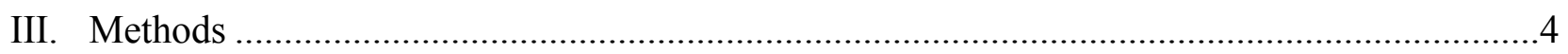

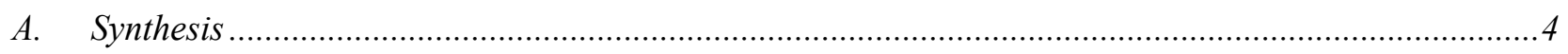

B. Fluorescence Quenching-Based Equilibrium Binding Assays ........................................................11

C. Binding Assays in the Presence of Urea ....................................................................................... 13

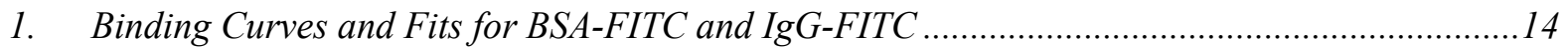

D. Binding Assays in the Presence of High Salt Concentration .......................................................15

1. Binding Curves and Fits for BSA-FITC, IgG-FITC, and Streptavidin-FITC with Higher Salt ...16

2. Binding Curves and Fits for $d G 15$ and BSA-FITC ...............................................................19

3. Binding Curves and Fits for dG15 and IgG-FITC in Comparison to Block Copolymer .............20

E. Binding Assays to Determine Salt Competition ..................................................................................20

F. $\quad$ Binding Assays using Unlabeled BSA as a Competitor .................................................................21

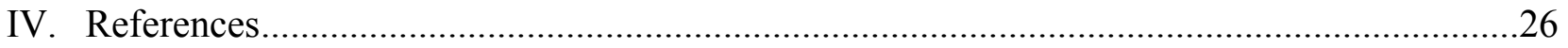




\section{Materials}

All proteins were purchased with dye labels and used without further purification. Albumin, fluorescein isothiocyanate conjugate from bovine (BSA-FITC) and anti-mouse IgG (whole molecule)-FITC produced in goat, affinity isolated antibody (IgG-FITC) were purchased from Sigma-Aldrich. Albumin from bovine serum (BSA) was purchased from Rockland Chemical. Recombinant streptavidin protein FITC ( $\sim 53 \mathrm{kDa}$, neutral isoelectric point) was purchased from Thermo Fisher Scientific, Inc. Dimethyl sulfoxide (DMSO) was purchased from Fisher Scientific and DMSO- $d_{6}$ and acetonitrile- $d_{3}$ were purchased from Cambridge Isotopes Laboratory, Inc. PBS Buffer, 10x, $\mathrm{pH} 7.4$, was purchased from Thermo Fisher Scientific, Inc and diluted to 1x or 3x concentration with Milli-Q water. Trifluoroacetic acid (TFA) was purchased from Alfa Aesar and used without further purification. Methanol, ethyl acetate, acetone, tetrahydrofuran, and dichloromethane were purchased from Fisher Scientific and used without further purification. Other chemicals and solvents not listed above were obtained as reagent grade from Millipore Sigma, Fluka, BDH, or Acros Organics and used as received unless otherwise noted. Grubbs 3rd generation catalyst (Dichloro-di(3-bromopyridino)-N,N'-Dimesitylenoimidazolino- $\mathrm{Ru}=\mathrm{CHPh}$; G3) was synthesized as described previously was synthesized as described previously. ${ }^{1}$ Polymers were dialyzed using Spectra/Por® dialysis membranes with molecular weight cutoffs (MWCOs) of $1 \mathrm{kDa}$.

\section{Instrumentation and Software}

A CombiFlash Rf 200 automated chromatography system (Teledyne ISCO) with 120 g RediSep Rf silica disposable columns was used to purify the MePh and dG monomers.

${ }^{1} \mathrm{H}$ nuclear magnetic resonance spectra were recorded for all monomers and polymers at $500 \mathrm{MHz}$ 
using a Bruker Ascend Nuclear Magnetic Resonance Spectrometer retrofitted with a cryoprobe. Chemical shifts $(\delta)$ are listed in ppm and coupling constants $(J)$ in $\mathrm{Hz}$.

Gel permeation chromatography (GPC) chromatograms were recorded for all polymers using an Agilent Technologies 1260 Infinity series system equipped with refractive index (RI) and ultraviolet (UV) detectors, a PL Gel $5 \mu \mathrm{m}$ guard column, two PL Gel $5 \mu \mathrm{m}$ analytical Mixed-C columns, and a PL Gel $5 \mu \mathrm{m}$ analytical Mixed-D column. Columns were connected in series and incubated at $40{ }^{\circ} \mathrm{C}$ with THF used as the eluent at a flow rate of $1 \mathrm{~mL} / \mathrm{min}$. Toluene was used as a flow marker. Molecular weight approximation of polymer samples was conducted against calibrated polystyrene standards. All samples were prepared at a concentration of $2-3 \mathrm{mg} / \mathrm{mL}$ and filtered into 1-dram vials using $0.45 \mu \mathrm{m}$ PTFE syringe filters prior to injection.

Fluorescence-based binding assays were conducted using a BioTek Instruments Synergy Mx plate reader with Gen5 1.10 software.

\section{Methods}

\section{A. Synthesis}

The following polymeric carriers have been previously reported and characterized: MePh10-b-

dG5 and $\mathbf{d G}_{\mathbf{1 5}}$. While reported before, both polymers were resynthesized for this study and will be briefly described here.

\section{Monomers}

All monomers were prepared following previously reported procedures. ${ }^{2,3}$ 


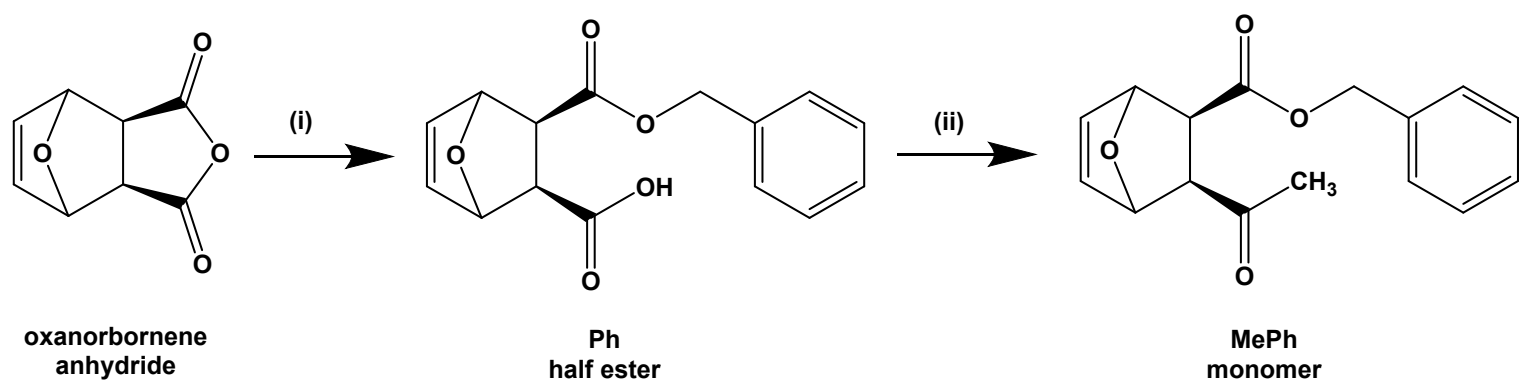

Figure S1: Synthesis of $\mathbf{P h}$ half ester monomer and $\mathbf{M e P h}$ monomer. (i) Benzyl alcohol, DMAP, $\mathrm{CH}_{2} \mathrm{Cl}_{2}$, room temperature, overnight; (ii) methanol, DMAP, $\mathrm{EDC}, \mathrm{CH}_{2} \mathrm{Cl}_{2}, 0{ }^{\circ} \mathrm{C}$ to room temperature, overnight.

Ph half ester: One molar equivalent of oxanorbornene anhydride and 0.1 molar equivalents of 4-dimethylaminopyridine (DMAP) were added to a flame-dried two-neck round bottom flask containing a stir bar while under nitrogen gas. Solid was dissolved in freshly distilled $\mathrm{CH}_{2} \mathrm{Cl}_{2}$ that had been dried over $\mathrm{CaH}_{2}$. One molar equivalent of benzyl alcohol was added via syringe. The reaction was stirred overnight under nitrogen at room temperature. The resulting precipitate was isolated by vacuum filtration, washed $3 \mathrm{x}$ with cold $\mathrm{CH}_{2} \mathrm{Cl}_{2}$, and then dried under vacuum.

$52.4 \%$ yield

${ }^{1} \mathrm{H}$ NMR (500 MHz, DMSO) $\delta=12.47(\mathrm{~s}, 1 \mathrm{H}), 7.37-7.34(\mathrm{~m}, 5 \mathrm{H}), 6.50-6.42(\mathrm{~m}, 2 \mathrm{H}), 5.11(\mathrm{~d}$, $2 \mathrm{H}), 5.06-4.98(\mathrm{~m}, 2 \mathrm{H}), 2.81-2.73(\mathrm{~m}, 2 \mathrm{H})$.

MePh monomer: One molar equivalent of the $\mathbf{P h}$ half ester and 0.1 molar equivalents of DMAP were added to a flame-dried two-neck round bottom flask containing a stir bar while under nitrogen gas. Solid was dissolved in freshly distilled $\mathrm{CH}_{2} \mathrm{Cl}_{2}$ that had dried over $\mathrm{CaH}_{2}$. One molar equivalent of methanol was added via syringe. Following the addition of methanol, the solution was allowed to mix and then was cooled down to $0^{\circ} \mathrm{C}$ in an ice-water bath and 1.2 molar equivalents of 1 -ethyl3-(3-dimethylaminopropyl)carbodiimide (EDC) were added. The solution was allowed to gradually return to room temperature and then stir overnight under nitrogen. The diester product 
was isolated by normal phase flash chromatography with silica using a 50/50 (v/v) mixture of $\mathrm{CH}_{2} \mathrm{Cl}_{2}$ /ethyl acetate (EtOAc) as the eluent. Pure fractions were combined and concentrated using rotary evaporation. The viscous oil was dried under vacuum overnight and then freeze-thawed in liquid nitrogen bath to obtain a white solid.

$86.0 \%$ yield

${ }^{1} \mathrm{H}$ NMR (500 MHz, DMSO) $\delta=7.41-7.32(\mathrm{~m}, 5 \mathrm{H}), 6.47(\mathrm{~s}, 2 \mathrm{H}), 5.15(\mathrm{~d}, J=8.5 \mathrm{~Hz}, 2 \mathrm{H})$, $5.09-5.01(\mathrm{~m}, 2 \mathrm{H}), 3.47(\mathrm{~s}, 3 \mathrm{H}), 2.90-2.83(\mathrm{~m}, 2 \mathrm{H})$.
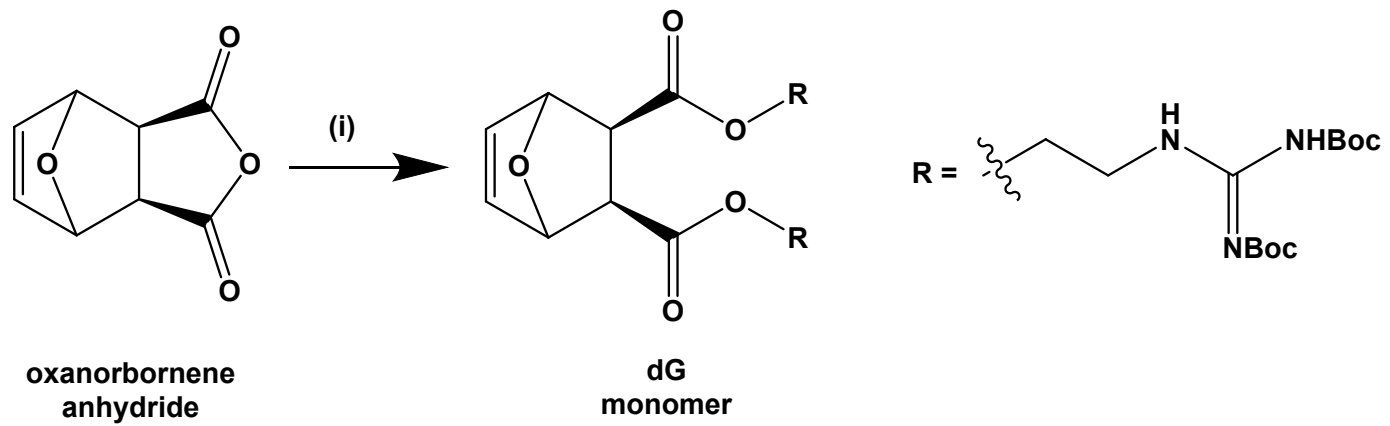

Figure S2: Synthesis of dG monomer. (i) R-OH, DMAP, EDC, $\mathrm{CH}_{2} \mathrm{Cl}_{2}, 0^{\circ} \mathrm{C}$ to room temperature, overnight.

dG monomer: One molar equivalent of oxanorbornene anhydride, two molar equivalents of 1,3,di-boc-2- (2-hydroxyethyl)guanidine, and 0.1 molar equivalents of DMAP were dissolved in freshly distilled $\mathrm{CH}_{2} \mathrm{Cl}_{2}$ dried over $\mathrm{CaH}_{2}$ and stirred at room temperature under nitrogen. The solution was then cooled down to $0{ }^{\circ} \mathrm{C}$ in an ice bath and 1.2 molar equivalents of EDC were added. The solution was allowed to stir overnight under nitrogen and gradually return to room temperature. The diester product was isolated by normal phase flash chromatography using silica using a 70/30 (v/v) mixture of $\mathrm{CH}_{2} \mathrm{Cl}_{2} / \mathrm{EtOAc}$ as the eluent. Pure fractions were combined and concentrated using rotary evaporation. The sample was dried under vacuum overnight at room temperature to obtain a white solid. 
${ }^{1} \mathrm{H} \mathrm{NMR}(500 \mathrm{MHz}, \mathrm{CDCl} 3) \delta=11.49$ (br, 2H), 8.56 (br, 2H), 6.48 (br, 2H), $5.32(\mathrm{~s}, 2 \mathrm{H})$, $4.29-4.25(\mathrm{~d}, 4 \mathrm{H}), 3.78-3.69(\mathrm{~d}, 4 \mathrm{H}), 2.86(\mathrm{br}, 2 \mathrm{H}), 1.50(\mathrm{~b}, 36 \mathrm{H})$.

\section{Polymers}

All polymers were prepared according to previously reported procedures. ${ }^{3}$

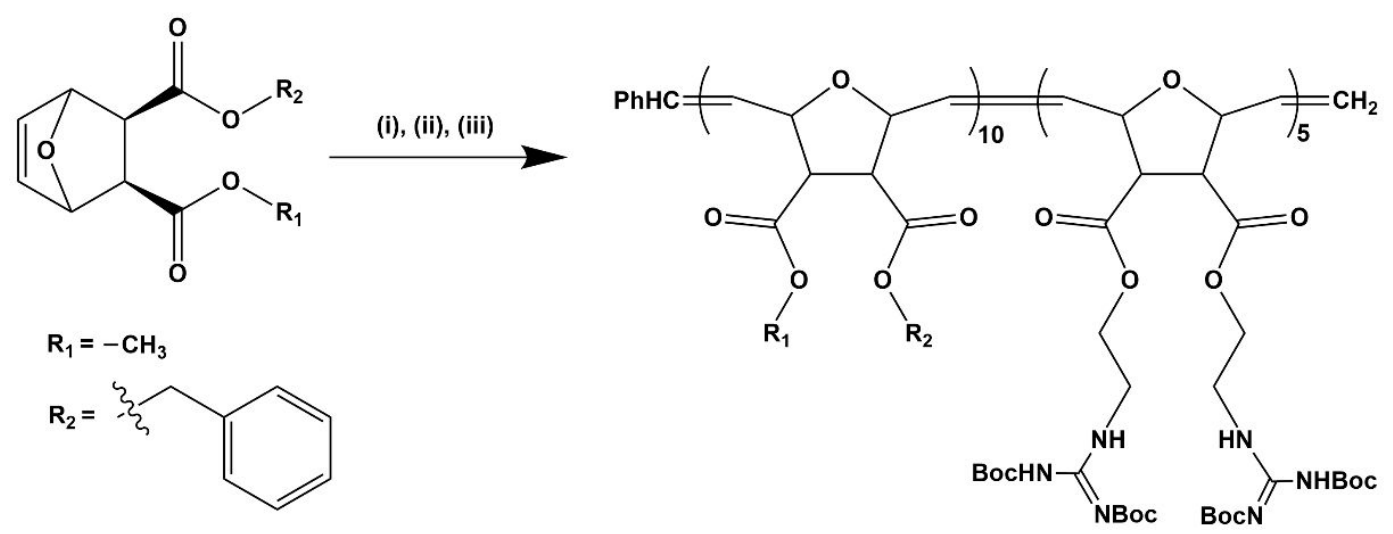

Figure S3: Synthesis of Boc-protected block copolymer. (i) $\mathrm{G} 3, \mathrm{CH}_{2} \mathrm{Cl}_{2}$, room temperature, 5-10 min; (ii) dG monomer, $\mathrm{CH}_{2} \mathrm{Cl}_{2}$, room temperature, $90 \mathrm{~min}$; (iii) ethyl vinyl ether, room temperature, overnight.

In brief, 1 molar equivalent of G3, 10 molar equivalents of the $\mathbf{M e P h}$ monomer and 5 molar equivalents of the $\mathbf{d G}$ monomer were dissolved in separate flame-dried Schlenk flasks using freshly distilled $\mathrm{CH}_{2} \mathrm{Cl}_{2}$ dried over $\mathrm{CaH}_{2}$. A stir bar was contained in the catalyst flask. The contents of all Schlenk flasks were put through a minimum of 3 freeze, pump, thaw (FPT) cycles to rigorously degas the monomer and catalyst solutions. After the final cycle, the contents of the flask containing the MePh monomer were cannulated into the flask containing the stirring G3 solution. This first monomer was allowed to polymerize for 5 - 10 minutes, at which time a crude aliquot was taken and dried using nitrogen gas for analysis by ${ }^{1} \mathrm{H}$ NMR and THF GPC. This NMR spectrum was used to confirm monomer conversion. The GPC chromatogram was used to calculate the molecular weight and dispersity of the firstblock. After the 5 minute period, $\mathbf{d G}$ monomer was cannulated into 
the flask containing G3 and the first monomer, and allowed to polymerize for an additional 90 minutes. An additional aliquot was taken at this time and dried using nitrogen gas for analysis by ${ }^{1} \mathrm{H}$ NMR and THF GPC to confirm addition of second monomer and block extension. Upon completion, $3 \mathrm{~mL}$ of ethyl vinyl ether (EVE) was injected into the Schlenk flask to terminate the polymerization. Reaction mixture was allowed to stir overnight, and then was concentrated to a film using rotary evaporation before it was redissolved in minimal amount of tetrahydrofuran (THF). Solution was precipitated dropwise into cold, stirring pentanes. The precipitated Bocprotected polymers were collected using vacuum filtration and dried under high vacuum overnight. Characterization of the precipitated Boc-protected polymers was conducted by ${ }^{1} \mathrm{H}$ NMR and THF GPC. The final NMR spectrum was used to calculate the relative block composition per previously established literature procedures. ${ }^{3}$

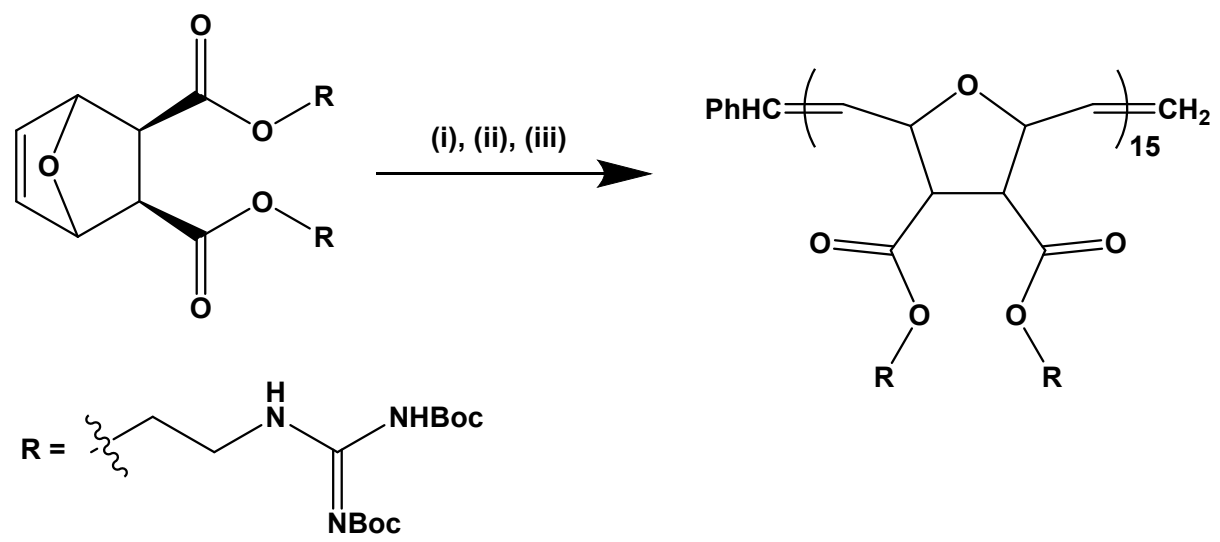

Figure S4: Synthesis of Boc-protected cationic homopolymers. (i) $\mathrm{G} 3, \mathrm{CH}_{2} \mathrm{Cl}_{2}$, room temperature, 90 min; (ii) ethyl vinyl ether, room temperature, overnight.

For $\mathbf{d G}_{15}, 1$ molar equivalent of $\mathrm{G} 3$ and 15 molar equivalents of the $\mathbf{d G}$ monomer were dissolved in separate flame-dried Schlenk flasks using freshly distilled $\mathrm{CH}_{2} \mathrm{Cl}_{2}$ dried over $\mathrm{CaH}_{2}$. Synthesis of $\mathbf{d G}_{\mathbf{1 5}}$ continued similarly to $\mathbf{M e P h}_{\mathbf{1 0}}-\mathbf{b}-\mathbf{d G}_{\mathbf{5}}$, except only one aliquot was taken for crude ${ }^{1} \mathrm{H}$ NMR and THF GPC analysis. 
Table S1: Polymer characterization summary from ${ }^{1} \mathrm{H}$ NMR and THF GPC analysis.

\begin{tabular}{|c|c|c|c|c|c|c|}
\hline Polymer & $\begin{array}{l}\text { Block 1: } \\
\text { Block 2a }\end{array}$ & $\begin{array}{l}\text { Theoretical } \\
\text { MW } \\
(\mathrm{g} / \mathrm{mol})^{b}\end{array}$ & $\begin{array}{c}\text { Mp } \\
(\mathrm{g} / \mathrm{mol})\end{array}$ & 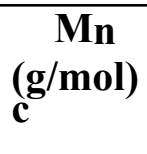 & $\begin{array}{c}\text { Mw } \\
(\mathrm{g} / \mathrm{mol})\end{array}$ & $\boldsymbol{\oplus}^{\mathbf{C}}$ \\
\hline $\mathrm{MePh}_{10}-b-\mathrm{dG}_{5}$ & $2: 1$ & 5899 & 7690 & 6666 & 7353 & 1.1 \\
\hline $\mathrm{dG}_{15}$ & $\mathrm{~N} / \mathrm{A}$ & 8841 & 9068 & 7635 & 8579 & 1.1 \\
\hline
\end{tabular}

aRelative block incorporation as calculated by ${ }^{1} \mathrm{H}$ NMR. ${ }^{\mathrm{b}}$ Theoretical molecular weight based on polymer structure shown in Figure S3. ${ }^{\mathrm{c}}$ Calculated by GPC in $\mathrm{THF}, 40^{\circ} \mathrm{C}$, flow rate $1 \mathrm{~mL} / \mathrm{min}$ with polystyrene standards and toluene as the flow marker.

The ${ }^{1} \mathrm{H}$ NMR chemical shifts for each precipitated, Boc-protected polymer are below. Overlays of the GPC chromatograms taken for each polymer (comparing crude and precipitated) can be found in Figures S5 and S6.

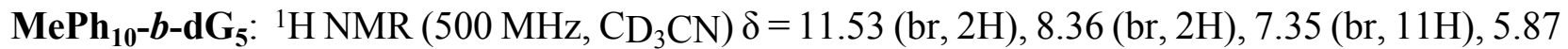

(trans) and 5.59 (cis) (br, 6H total), 5.08 (br, 4H), 5.00 (cis) and 4.65 (trans) (br, 6H total), 4.18 (br, 4H), 3.56 (br, 4H), 3.46 (br, 6H), 3.15 (br, 6H), 1.47 (d, 36H)

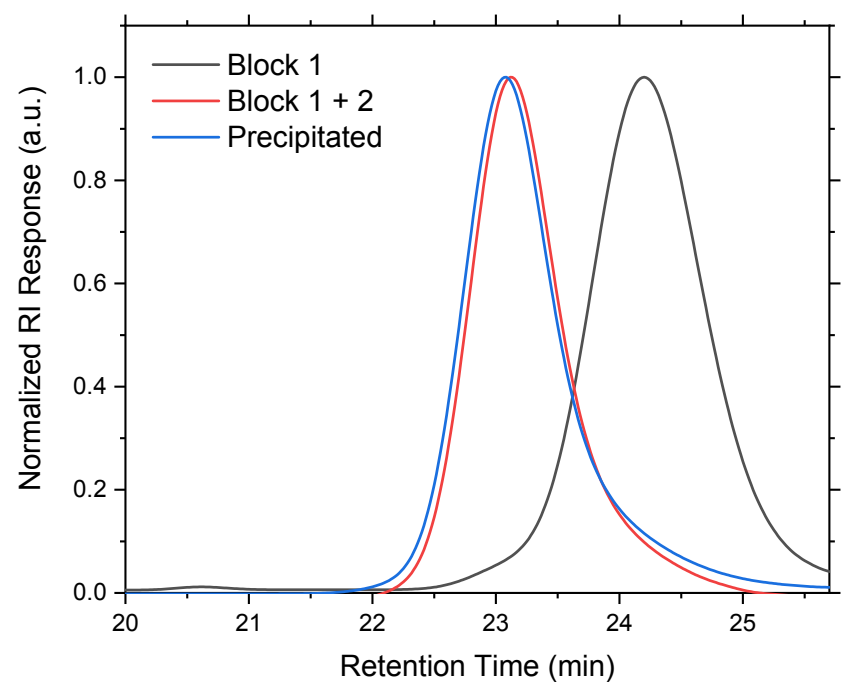

Figure S5: GPC traces illustrating the increase in molecular weight upon chain extension of the first block (containingjust the $\mathbf{M e P h}$ monomer, black) to create the Boc-protected copolymer $\left(\mathbf{M e P h}_{\mathbf{1 0}^{-}}\right.$ b-dG $\mathbf{d}_{\mathbf{5}}$ ), shown here before (Block $1+2$, red) and after purification by precipitation (Precipitated, blue) 
$\mathbf{d G}_{15}:{ }^{1} \mathrm{H}$ NMR $\left(500 \mathrm{MHz}, \mathrm{CD}_{3} \mathrm{CN}\right) \delta=11.49$ (br, 2H), 8.34 (br, 2H), 5.85 (trans) and 5.59 (cis) (br, 2H total), 5.05 (cis) and 4.64 (trans) (br, $2 \mathrm{H}$ total), 4.15 (br, $4 \mathrm{H}), 3.54$ (br, 4H), 3.16 (br, 2H), 1.45 (s, $18 \mathrm{H}), 1.41(\mathrm{~s}, 18 \mathrm{H})$.

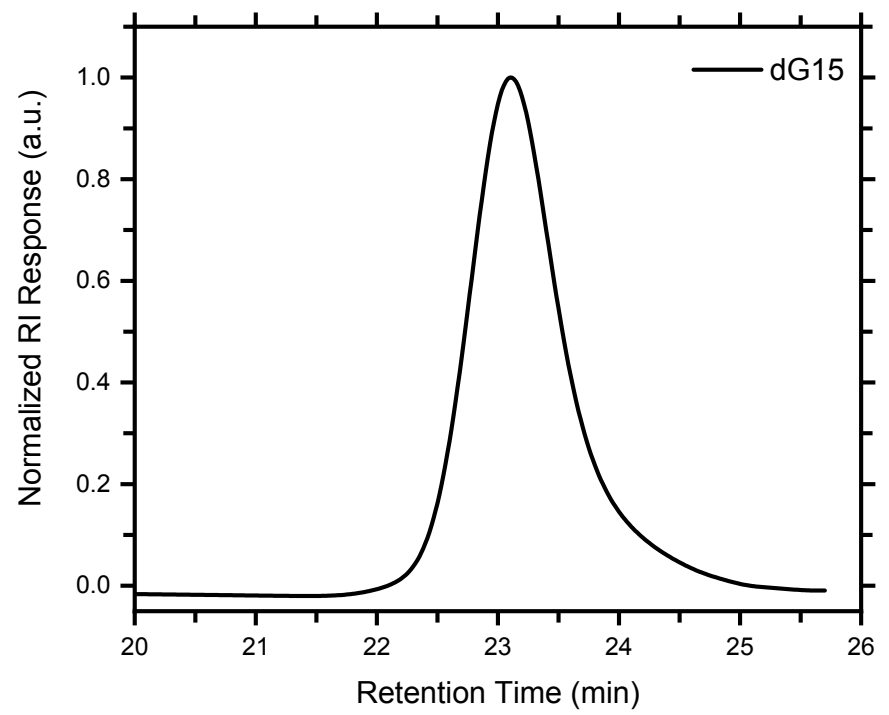

Figure S6: GPC trace illustrating the successful synthesis of Boc-protected homopolymer $\left(\mathbf{d G}_{\mathbf{1 5}}\right)$.

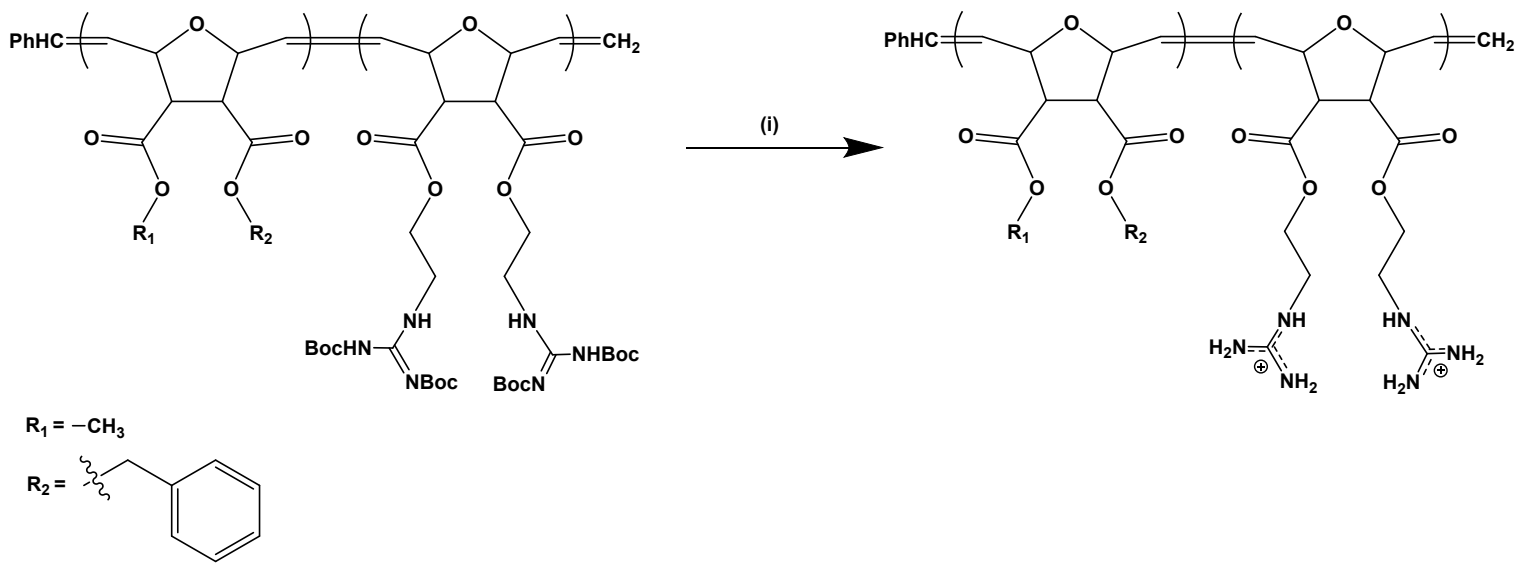

Figure S7: Deprotection of Boc-protected block copolymer to yield cationic guanidinium groups. (i) $\mathrm{TFA} / \mathrm{CH}_{2} \mathrm{Cl}_{2}$ (1:1), room temperature, overnight. Reaction not shown for homopolymer.

Following precipitation, polymers were deprotected in a $4 \mathrm{~mL}$ solution of 1:1 $\mathrm{CH}_{2} \mathrm{Cl}_{2}$ :trifluoroacetic acid (TFA) and stirred in a loosely capped scintillation vial overnight. In order to remove TFA, an azeotropic distillation with methanol was conducted. This process was repeated up to 7 times to remove traces of TFA. The deprotected polymers were then dissolved in a minimal volume of methanol, diluted in approximately $10 \mathrm{~mL}$ of reverse osmosis (RO) water, 
and loaded into hydrated dialysis membrane tubing (molecular weight cut off of $1000 \mathrm{Da}$ ). All polymers were dialyzed against RO water until the conductivity of the solution outside of the bag reached $0.5 \mu \mathrm{S}$ or lower, approximately $4-5$ days. Once dialysis was completed, polymer solutions were flash frozen in liquid nitrogen, and then isolated by lyophilization over the course of 5 days.

\section{B. Fluorescence Quenching-Based Equilibrium Binding Assays}

To determine the binding behavior for various carrier:protein complexes equilibrium fluorescence quenching assays were conducted according to previously published procedures. ${ }^{2,8,10}$ These assays were conducted at $25^{\circ} \mathrm{C}$ in PBS at $\mathrm{pH} \sim 7.2$ and the fluorescence of FITC-labelled proteins was monitored and recorded as a function of increasing carrier concentration (from 0 up to $80 \mu \mathrm{M}$, depending on protein). These experiments were conducted in a 96-well polystyrene plate, where each well had black opaque sides and flat clear bottoms. In general, each well in the titration contained $200 \mathrm{nM}$ of respective protein concentration, the respective carrier concentration, and remaining PBS for a total volume of $200 \mu \mathrm{L}$. Stock concentrations of $\sim 1 \mathrm{mg} / \mathrm{mL}, 1.1 \mathrm{mg} / \mathrm{mL}$, and $1 \mathrm{mg} / \mathrm{mL}$ were used for BSA-FITC, IgG-FITC, and Streptavidin-FITC, respectively. Aliquots of stock concentrations were removed and subsequently diluted to yield a working solution of dyelabelled protein. Carrier stock concentrations of $1 \mathrm{mM}$ in pure DMSO were serially diluted in PBS to produce subsequent stock solutions of $100 \mu \mathrm{M}(10 \% \mathrm{v} / \mathrm{v}$ DMSO) or $10 \mu \mathrm{M}(1 \% \mathrm{v} / \mathrm{v}$ DMSO). As the use of different carrier stock solutions introduced DMSO in varying amounts, additional DMSO was added to each well such that all wells contained the same concentration(v/v) of DMSO. Once all wells had received the calculated volumes of PBS, protein, DMSO and the appropriate carrier, they were gently mixed by pipetting up and down and stirring with the tip of the pipet. The 96-well plate was allowed to incubate in the dark (covered by the plastic lid and under foil) at room 
temperature for $30 \mathrm{~min}$ to achieve equilibrium prior to fluorescence measurements. For each respective protein, an initial absorbance spectrum was run in order to determine optimal excitation and emission wavelengths for FITC-Conjugated proteins. BSA-FITC samples were excited at 495 $\mathrm{nm}$ and emission was read at $523 \mathrm{~nm}$, Streptavidin-FITC samples were excited at $496 \mathrm{~nm}$ and emission read at $519 \mathrm{~nm}$, and IgG-FITC samples were excited at $495 \mathrm{~nm}$ and emission read at $520 \mathrm{~nm}$. During the binding experiments, the fluorescence intensity of each well in the titration for a given protein was measured. The background noise of a negative control (containing only PBS and DMSO) was first subtracted from these measurements. Next, the values were normalized by the fluorescence intensity of a positive control (containing only $200 \mathrm{nM}$ protein, PBS, and DMSO) to yield a curve of normalized fluorescence intensity vs. carrier concentration. Unless otherwise noted, binding experiments were repeated in triplicate for each carrier. Data were also converted to fractional saturation and the equilibrium dissociation constant $\left(\mathrm{K}_{\mathrm{d}}\right)$ was calculated as reported previously. $^{4}$ 
1. Binding Curves and Fits for BSA-FITC, IgG-FITC, and Streptavidin-FITC

BSA-FITC

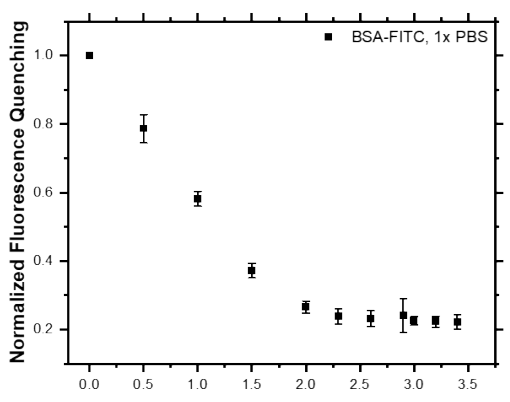

Polymer Concentration ( $\mu \mathrm{M})$

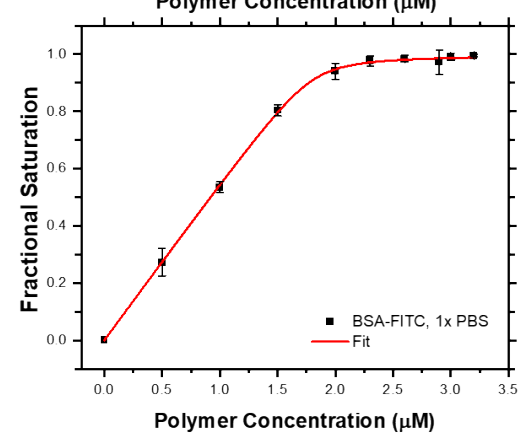

$\mathrm{Kd}=16.0+/-2.6$

$\mathrm{n}=9.0+/-0.1$

$\mathrm{R}$-Square $=0.999$
Streptavidin-FITC
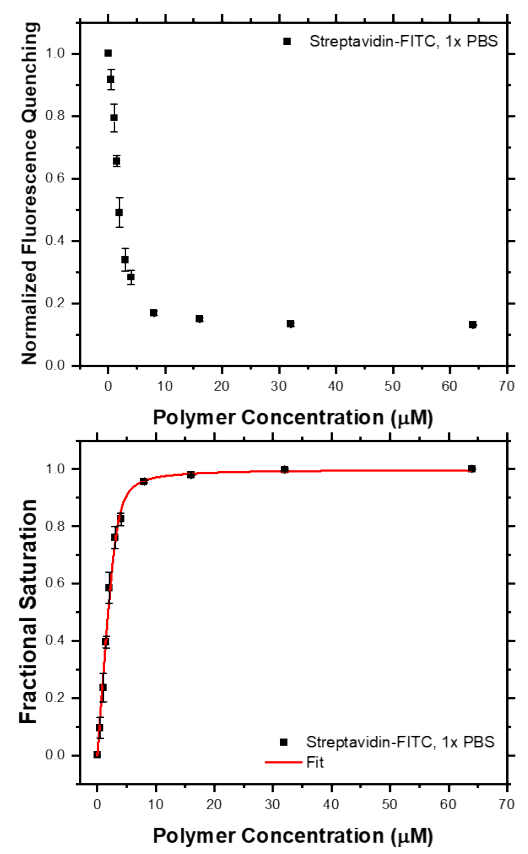

$\mathrm{Kd}=203.5+/-76.1$

$\mathrm{n}=16.4+/-1.3$

R-Square $=0.994$
IgG-FITC
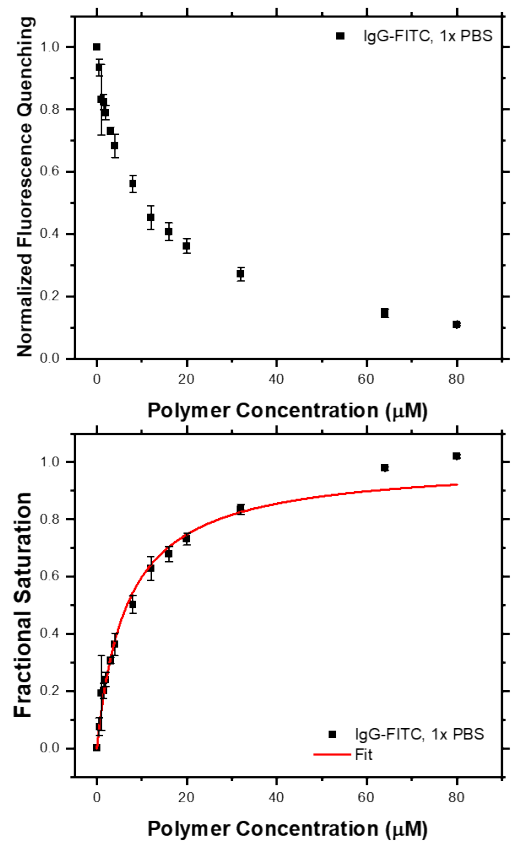

$\mathrm{Kd}=6,805+/-1,151$

$\mathrm{n}=-1.4+/-10.5$

R-Square $=0.984$

Figure S8a: Top row: $\mathbf{M e P h}_{\mathbf{1 0}} \mathbf{- b}-\mathbf{d G}_{\mathbf{5}}$ and protein binding curves (BSA-FITC, Streptavidin-FITC, or IgG-FITC from left to right). Data obtained from three independent trials where error bars represent \pm one standard deviation. Bottom row: Polymer and protein (BSA-FITC, Streptavidin-FITC, or IgGFITC from left to right) fractional saturation plots and fitting per previously established methods, where $\mathrm{K}_{\mathrm{d}}$ is the dissociation constant and $\mathrm{n}$ is the calculated number of binding sites. ${ }^{4}$ The calculated r-square of the non-linear least squares regression fit is also included.

BSA-FITC

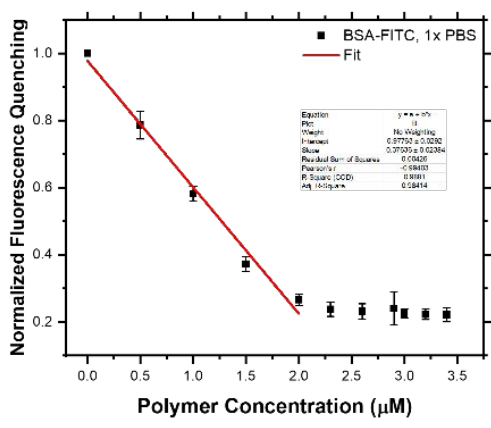

X-axis intercept: $2.6 \mu \mathrm{M}$
Streptavidin-FITC

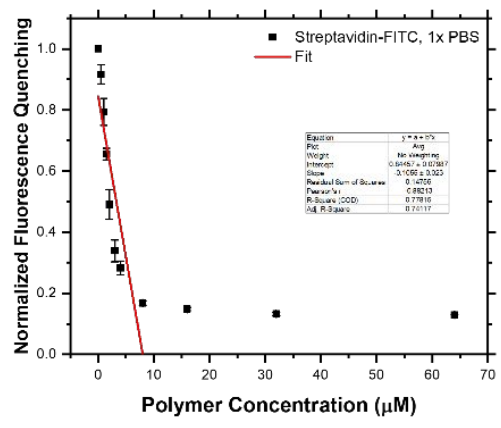

X-axis intercept: $8.0 \mu \mathrm{M}$
IgG-FITC

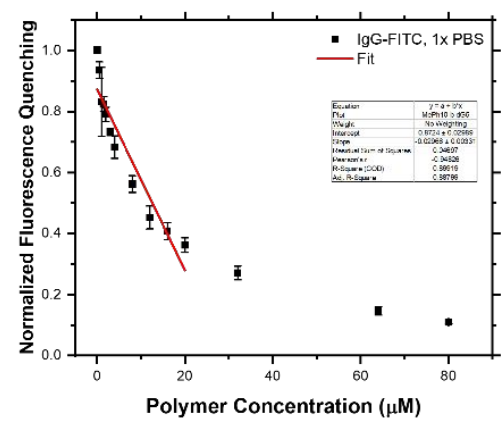

X-axis intercept: $29.4 \mu \mathrm{M}$

Figure S8b: $\mathbf{M e P h}_{\mathbf{1 0}} \mathbf{- b}-\mathbf{d G}_{\mathbf{5}}$ and protein binding curves (BSA-FITC, Streptavidin-FITC, or IgG-FITC from left to right) shown in Figure S8, but with additional linear fit drawn to indicate changes in initial slope and $\mathrm{x}$-axis intercept. Data obtained from three independent trials where error bars 
represent \pm one standard deviation.

\section{Binding Assays in the Presence of Urea}

In order to probe the role of hydrogen bonding interactions in polymer-protein binding, urea was added to the 1x PBS used for fluorescence quenching assays. Urea crystals were weighed out and dissolved in a stock solution of regular 1x PBS that was then used throughout the entire binding experiment, including all dilutions of protein and polymer stock. For the creation of $500 \mathrm{mM}$ ureacontaining PBS, approximately $300.3 \mathrm{mg}$ of urea crystals were dissolved in $10 \mathrm{~mL} 1 \mathrm{x}$ PBS. For the creation of $2 \mathrm{M}$ urea-containing PBS, approximately 1,201.2 $\mathrm{mg}$ of urea crystals were dissolved in $10 \mathrm{~mL} 1 \mathrm{x}$ PBS. The $\mathrm{pH}$ of these solutions were verified to be 7.2 , similar to $1 \mathrm{x}$ PBS with no urea added. The urea experiments were conducted in duplicate which included weighing out of urea as a solid.

1. Binding Curves and Fits for BSA-FITC and IgG-FITC

BSA-FITC, 0 M Urea
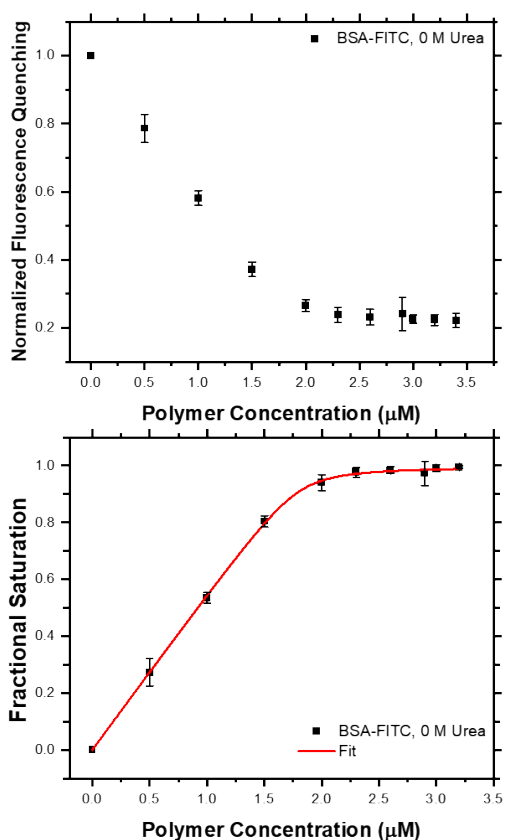

$\mathrm{Kd}=16.0+/-2.6$

$\mathrm{n}=9.0+/-0.1$

R-Square $=0.999$
BSA-FITC, $0.5 \mathrm{M}$ Urea
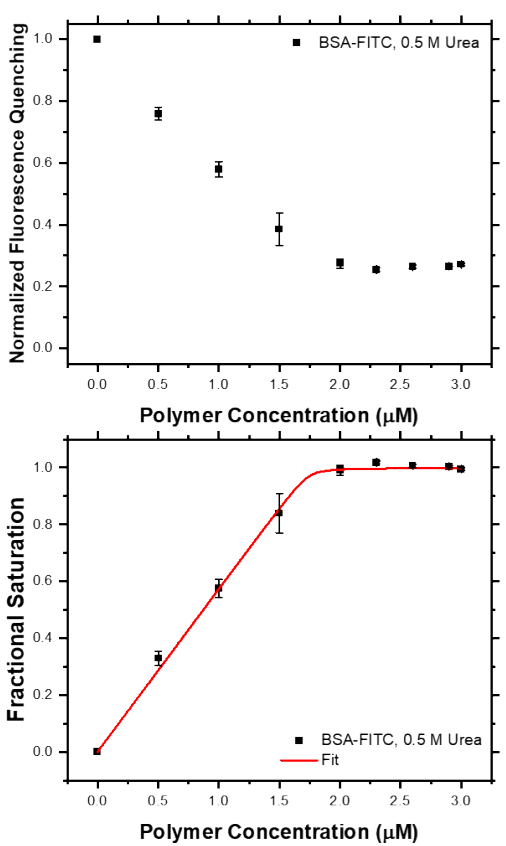

$\mathrm{Kd}=1.8+/-4.5$

$\mathrm{n}=8.7+/-0.2$

$\mathrm{R}$-Square $=0.997$
BSA-FITC, 2 M Urea
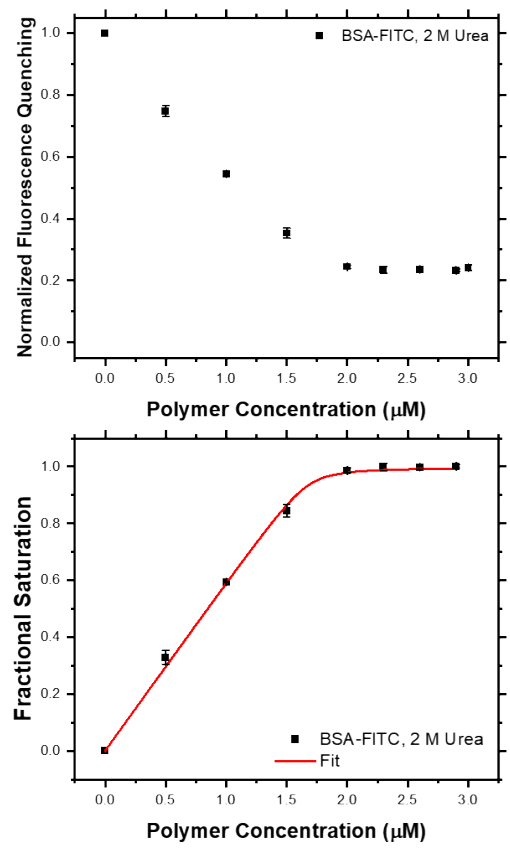

$\mathrm{Kd}=7.6+/-5.3$

$\mathrm{n}=8.4+/-0.2$

R-Square $=0.998$ 
Figure S9: Top row: $\mathbf{M e P h}_{\mathbf{1 0}} \mathbf{b}-\mathbf{d G}_{\mathbf{5}}$ and BSA-FITC binding curves for three conditions: in the presence of $0 \mathrm{M}$ urea (or 1x PBS), $0.5 \mathrm{M}$ urea, and $2 \mathrm{M}$ urea (left to right). Data obtained from three independent trials where error bars represent \pm one standard deviation. Bottom row: Polymer and protein fractional saturation plots and fitting per previously established methods, where $\mathrm{K}_{\mathrm{d}}$ is the dissociation constant and $\mathrm{n}$ is the calculated number of binding sites. ${ }^{4}$ The calculated $r$-square of the non-linear least squares regression fit is also included.
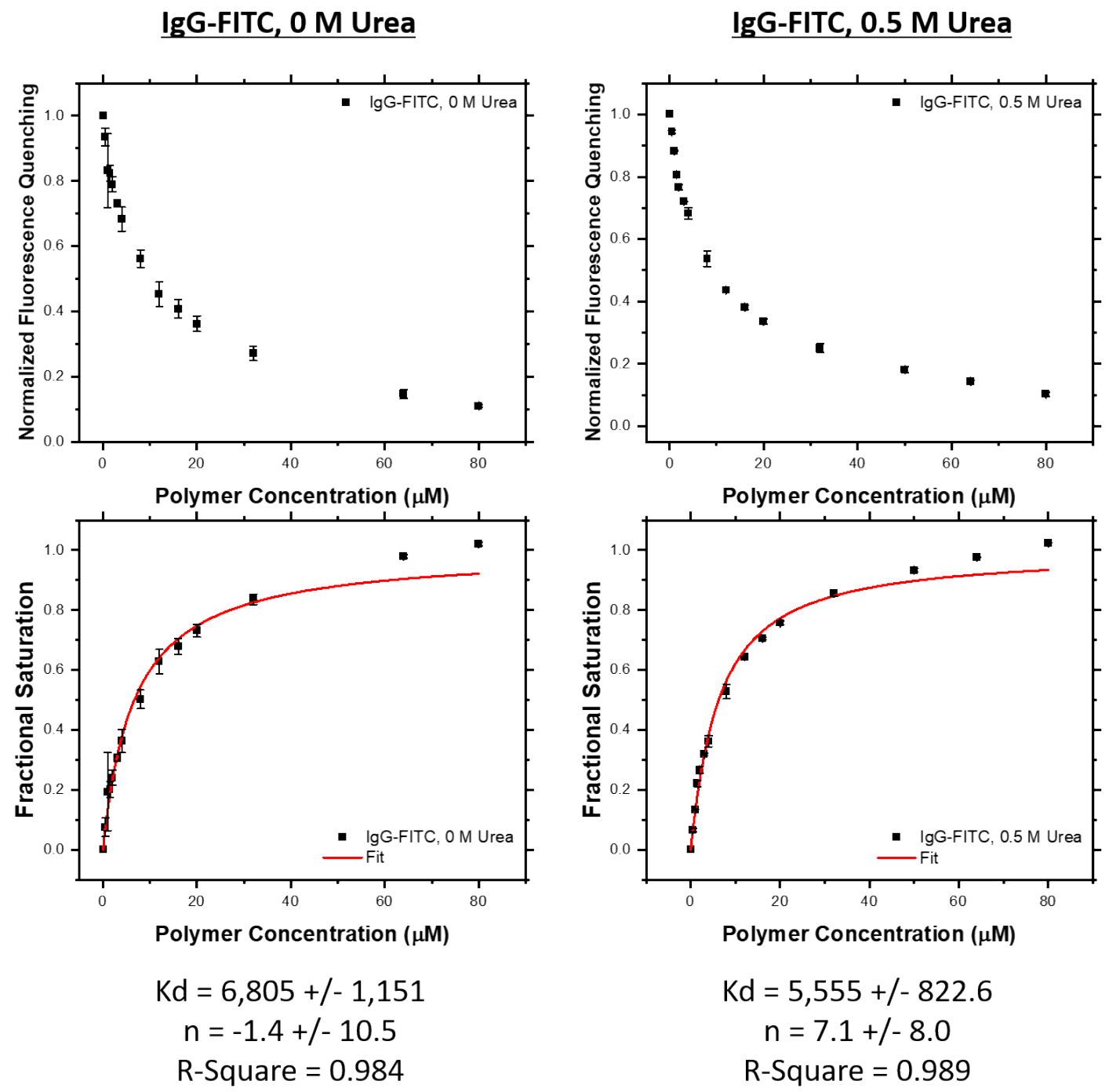

Figure S10: Top row: $\mathbf{M e P h}_{\mathbf{1 0}} \mathbf{- b}-\mathbf{d G}_{\mathbf{5}}$ and IgG-FITC binding curves for two conditions: in the presence of $0 \mathrm{M}$ urea (or $1 \mathrm{x}$ PBS) and $0.5 \mathrm{M}$ urea (left to right). Data obtained from three independent trials where error bars represent \pm one standard deviation. Bottom row: Polymer and protein fractional saturation plots and fitting per previously established methods, where $\mathrm{K}_{\mathrm{d}}$ is the dissociation constant and $\mathrm{n}$ is the calculated number of binding sites. ${ }^{4}$ The calculated $\mathrm{r}$-square of the non-linear least squares regression fit is also included.

D. Binding Assays in the Presence of High Salt Concentration 
In order to probe the role of electrostatic interactions in polymer-protein binding, various concentrations of buffered PBS was used for fluorescence quenching assays. As 10x PBS is commercially available from Gibco $(\mathrm{pH}$ 7.4), this was used as the highest salt-containing concentration of PBS. 10x PBS was diluted with MilliQ water to either 3x PBS or 1x PBS, depending on the desired salt concentration. A table of total salt concentrations (adapted from Thermofisher's website for 10x PBS for product number: 70011-044 and calculated for the subsequent 3x and 1x dilutions) is provided below (Table S2). These solutions of varying salt concentration were used throughout the entire binding experiment, including all dilutions of protein and polymer stock. Saltcontaining experiments were conducted in triplicate which included the dilution of 10x PBS to $3 x$ or 1x PBS.

Table S2: Approximate salt concentrations for 1x PBS, 3x PBS, and 10x PBS used for fluorescence binding assays.

\begin{tabular}{|c|c|c|c|}
\hline & 1x PBS & 3x PBS & 10x PBS \\
\hline $\begin{array}{c}\text { Potassium phosphate } \\
\text { monobasic }\end{array}$ & $1.06 \mathrm{mM}$ & $3.18 \mathrm{mM}$ & $10.59 \mathrm{mM}$ \\
\hline Sodium chloride & $155.17 \mathrm{mM}$ & $466.0 \mathrm{mM}$ & $1551.72 \mathrm{mM}$ \\
\hline $\begin{array}{c}\text { Sodium phosphate } \\
\text { dibasic }\end{array}$ & $2.97 \mathrm{mM}$ & $8.91 \mathrm{mM}$ & $29.66 \mathrm{mM}$ \\
\hline
\end{tabular}

1. Binding Curves and Fits for BSA-FITC, IgG-FITC, and Streptavidin-FITC with Higher Salt 

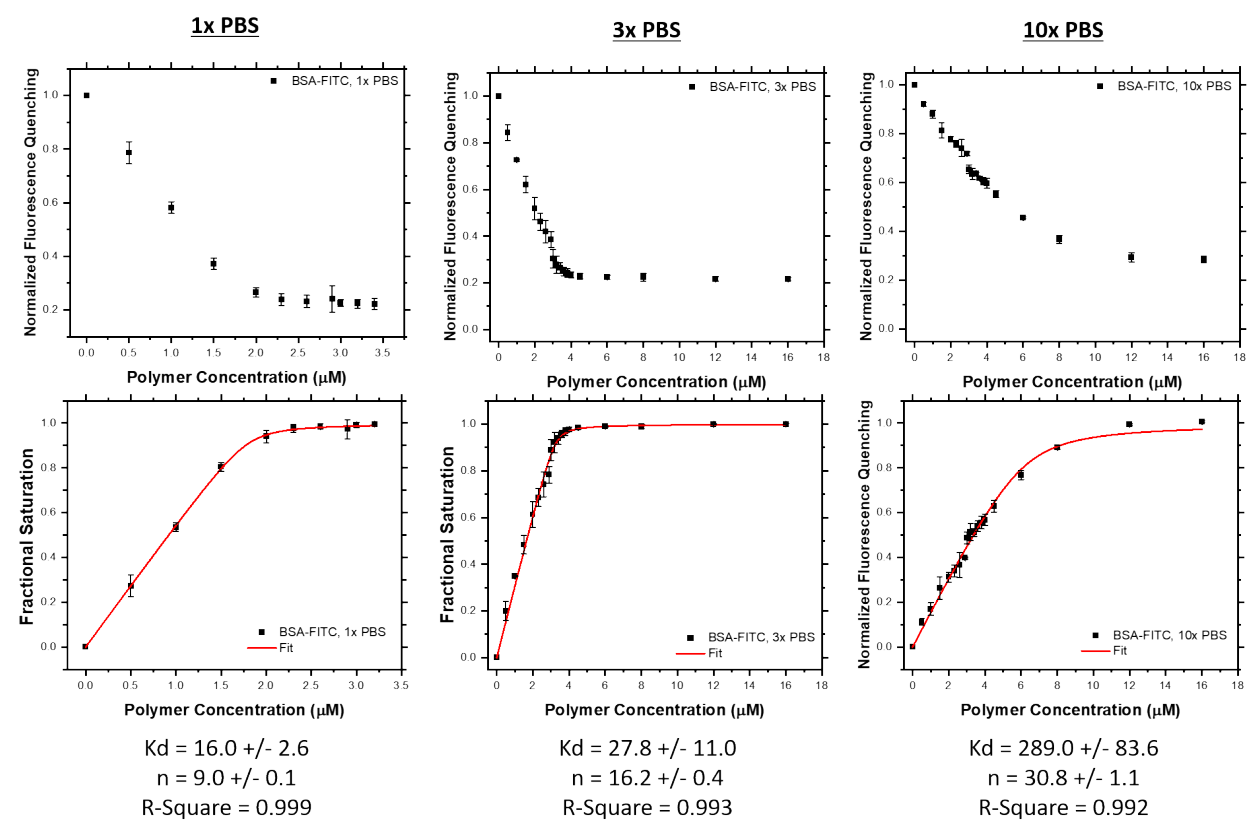

Figure S11: Top row: $\mathbf{M e P h}_{\mathbf{1 0}} \mathbf{- b}-\mathbf{d G}_{\mathbf{5}}$ and BSA-FITC binding curves for three conditions: $1 \mathrm{x}$ PBS, 3x PBS, and 10x PBS (from left to right). Data obtained from three independent trials where error bars represent \pm one standard deviation. Bottom row: Polymer and protein fractional saturation plots and fitting per previously established methods, where $K_{d}$ is the dissociation constant and $n$ is the calculated number of binding sites. ${ }^{4}$ The calculated r-square of the non-linear least squares regression fit is also included. 
1x PBS
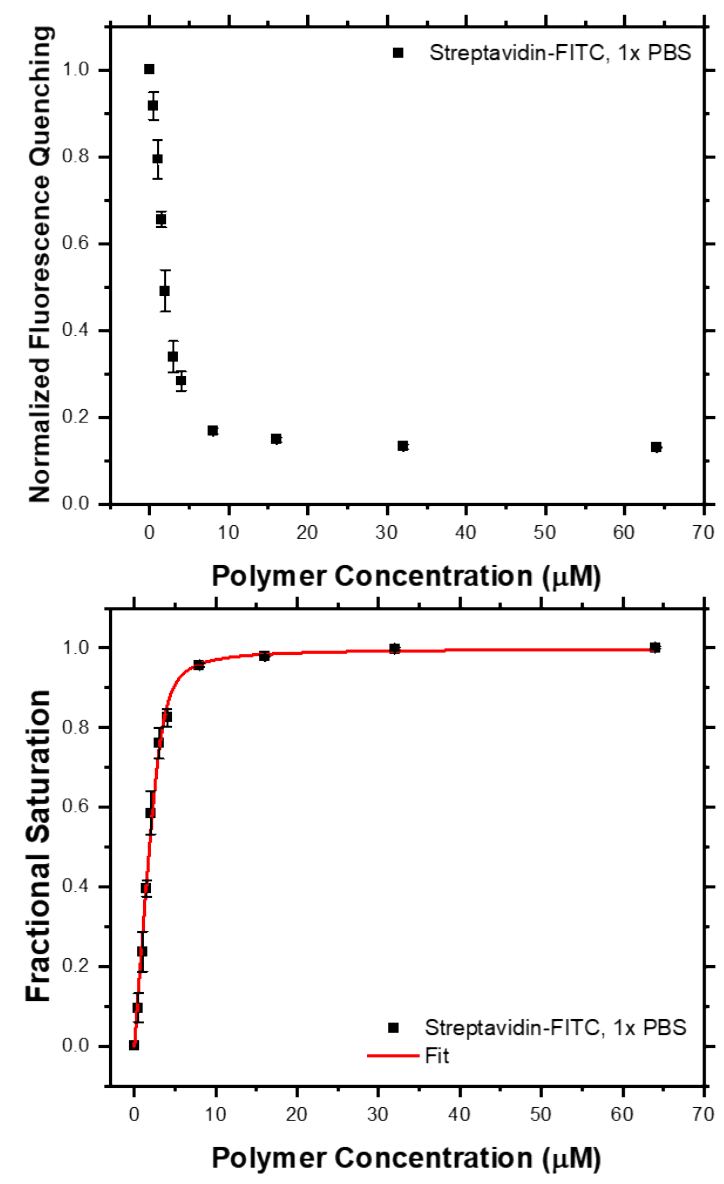

$$
\begin{gathered}
\mathrm{Kd}=203.5+/-76.1 \\
\mathrm{n}=16.4+/-1.3 \\
\text { R-Square }=0.994
\end{gathered}
$$

\section{0x PBS}

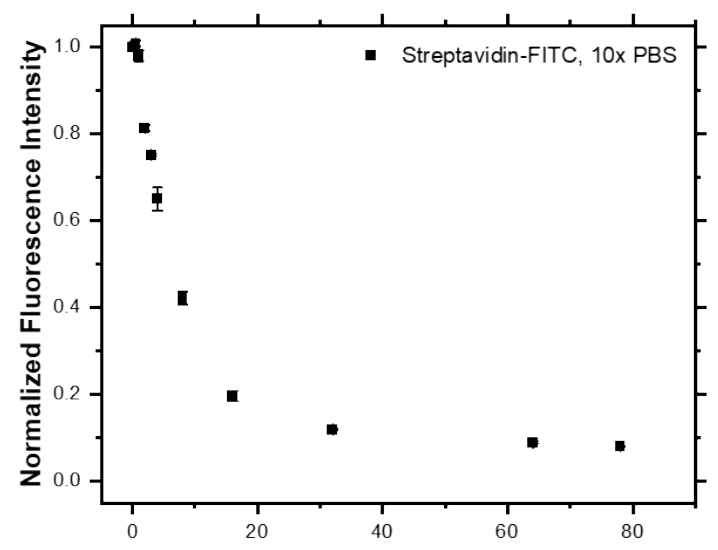

Polymer Concentration $(\mu \mathrm{M})$

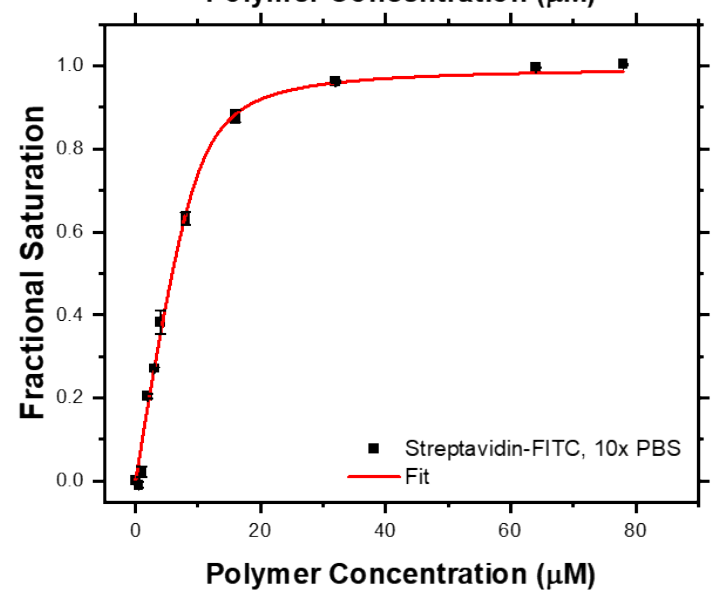

$$
\begin{gathered}
\mathrm{Kd}=962.8+/-366.5 \\
\mathrm{n}=49.0+/-5.1 \\
\mathrm{R} \text {-Square }=0.994
\end{gathered}
$$

Figure S12: Top row: $\mathbf{M e P h}_{\mathbf{1 0}} \mathbf{- b}-\mathbf{d G}_{\mathbf{5}}$ and Streptavidin-FITC binding curves for two conditions: $1 \mathrm{x}$ PBS and 10x PBS (from left to right). Data obtained from two independent trials where error bars represent \pm one standard deviation. Bottom row: Polymer and protein fractional saturation plots and fitting per previously established methods, where $\mathrm{K}_{\mathrm{d}}$ is the dissociation constant and $\mathrm{n}$ is the calculated number of binding sites. ${ }^{4}$ The calculated r-square of the non-linear least squares regression fit is also included. 
$\underline{\text { 1x PBS }}$
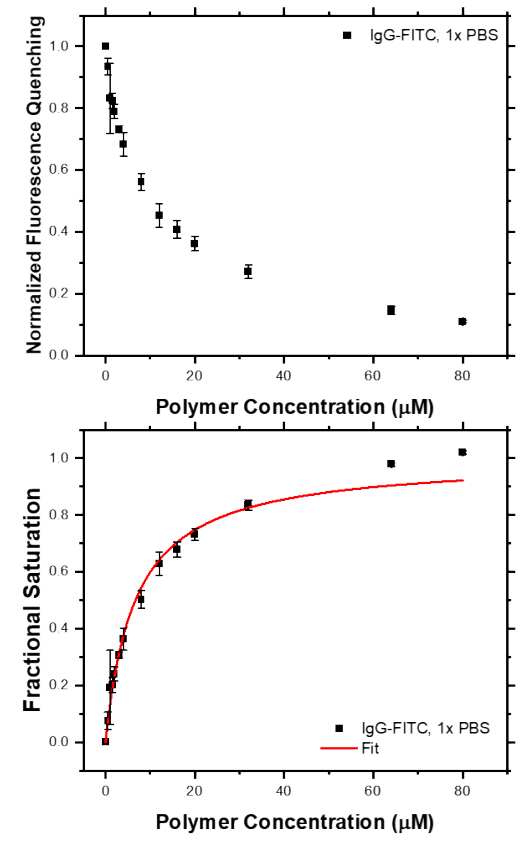

$\mathrm{Kd}=6,805+/-1,151$

$\mathrm{n}=-1.4+/-10.5$

$\mathrm{R}$-Square $=0.984$ 10x PBS
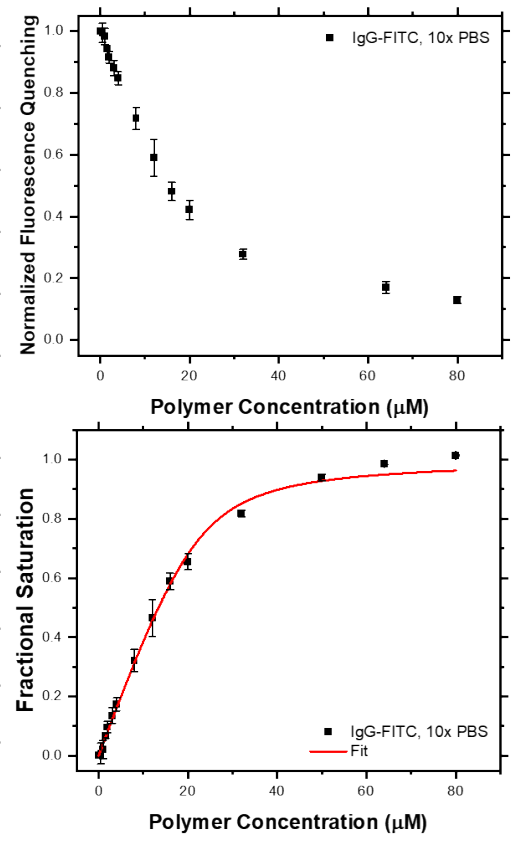

$\mathrm{Kd}=2,291+/-491$

$\mathrm{n}=110.8+/-7.2$

$\mathrm{R}$-Square $=0.996$
Overlay:

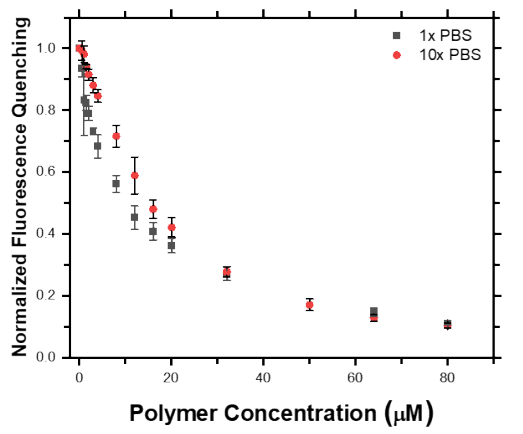

Polymer Concentration $(\mu \mathrm{M})$

Figure S13: Top row: $\mathbf{M e P h}_{\mathbf{1 0}} \mathbf{- b}-\mathbf{d G}_{\mathbf{5}}$ and IgG-FITC binding curves for two conditions: 1x PBS and 10x PBS (from left to right). In far right, two conditions are overlaid to demonstrate insignificant differences. Data obtained from three independent trials where error bars represent \pm one standard deviation. Bottom row: Polymer and protein fractional saturation plots and fitting per previously established methods, where $\mathrm{K}_{\mathrm{d}}$ is the dissociation constant and $\mathrm{n}$ is the calculated number of binding sites. ${ }^{4}$ Previous calculations of $\mathbf{M e P h}_{\mathbf{1 0}} \mathbf{- b}-\mathbf{d G}_{\mathbf{5}}$ and IgG-FITC binding have resulting in values of $\sim 5 \mu \mathrm{M}$, and discrepancies in these values are believed to be due to poorer fits. The calculated r-square of the non-linear least squares regression fit is also included. 
2. Binding Curves and Fits for $\mathbf{d G 1 5}$ and BSA-FITC

$\underline{1 \times}$ PBS
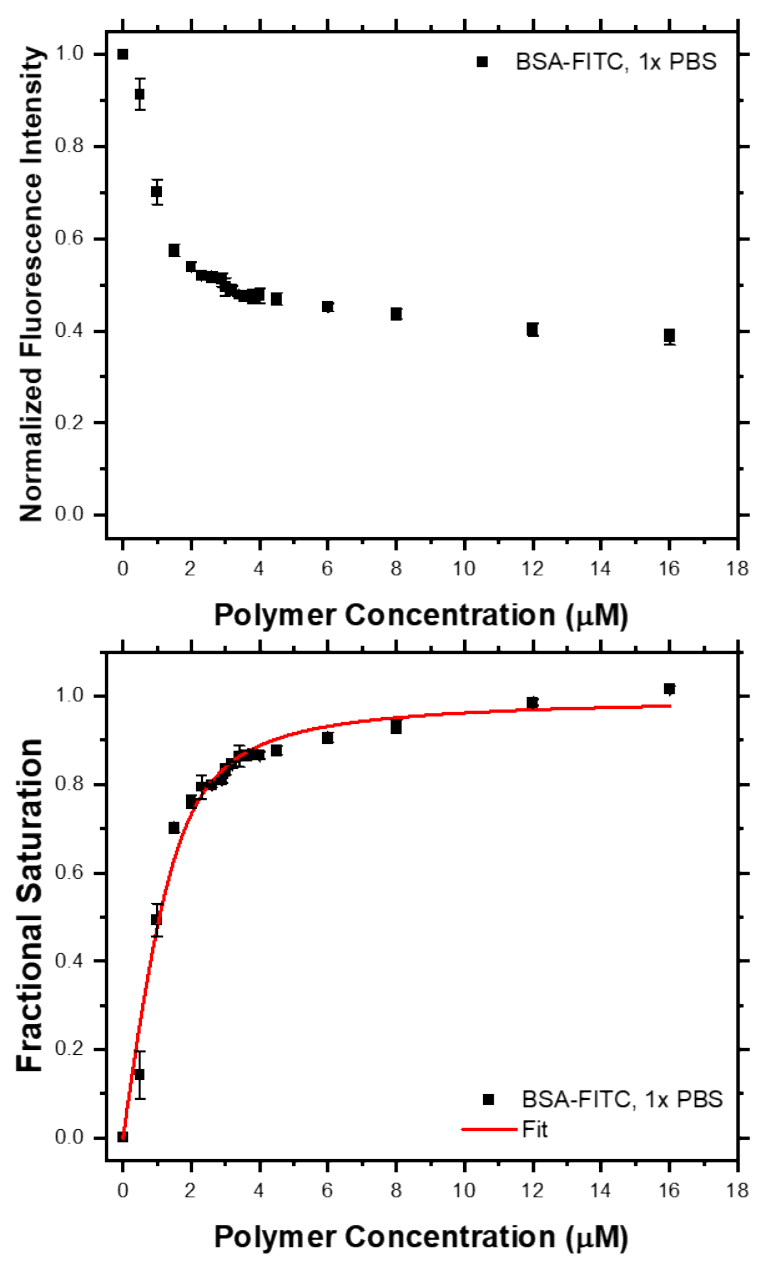

$\mathrm{Kd}=341+/-58.4$

$\mathrm{n}=7.3+/-1.1$

R-Square $=0.979$ 3x PBS
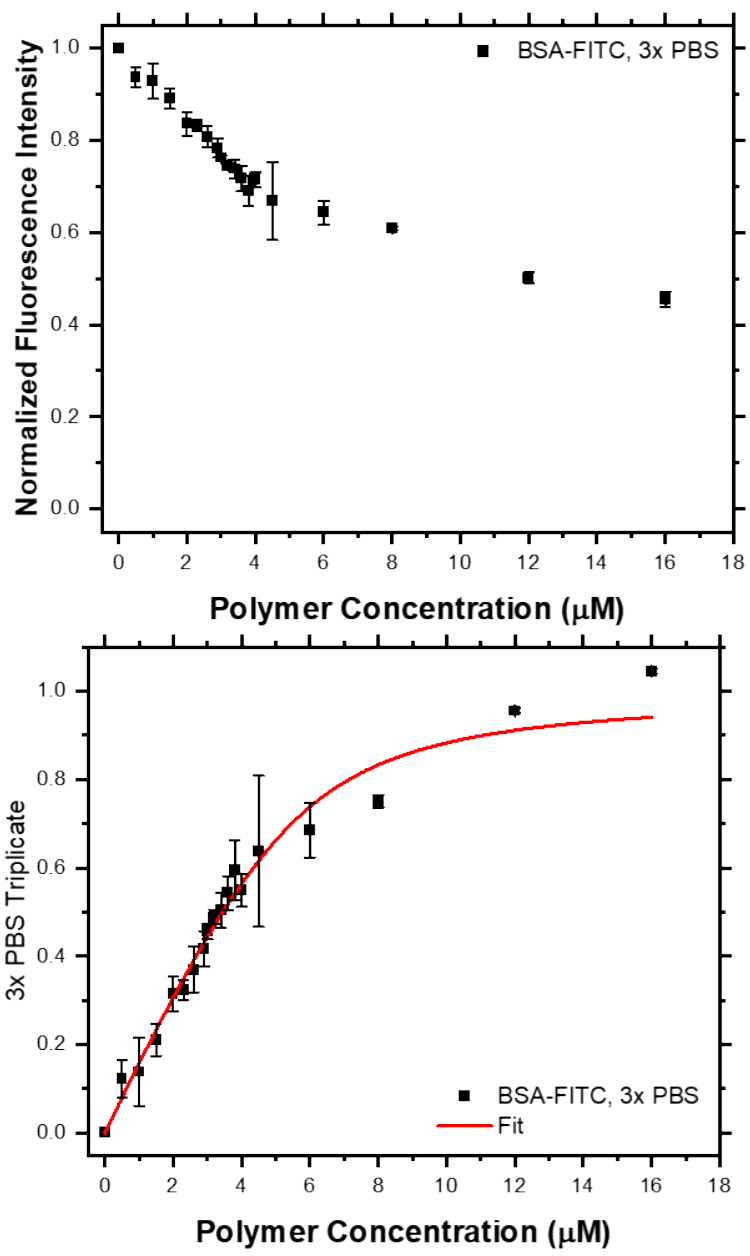

$$
\begin{gathered}
\mathrm{Kd}=678+/-222 \\
\mathrm{n}=27.7+/-2.6 \\
\text { R-Square }=0.976
\end{gathered}
$$

Figure S14: Top row: $\mathbf{d G}_{15}$ and BSA-FITC binding curves for two conditions: 1x PBS and 10x PBS (from left to right). Data obtained from three independent trials where error bars represent \pm one standard deviation. Bottom row: Polymer and protein fractional saturation plots and fitting per previously established methods, where $\mathrm{K}_{\mathrm{d}}$ is the dissociation constant and $\mathrm{n}$ is the calculated number of binding sites. ${ }^{4}$ The calculated $r$-square of the non-linear least squares regression fit is also included. 
3. Binding Curves and Fits for dG15 and IgG-FITC in Comparison to Block Copolymer

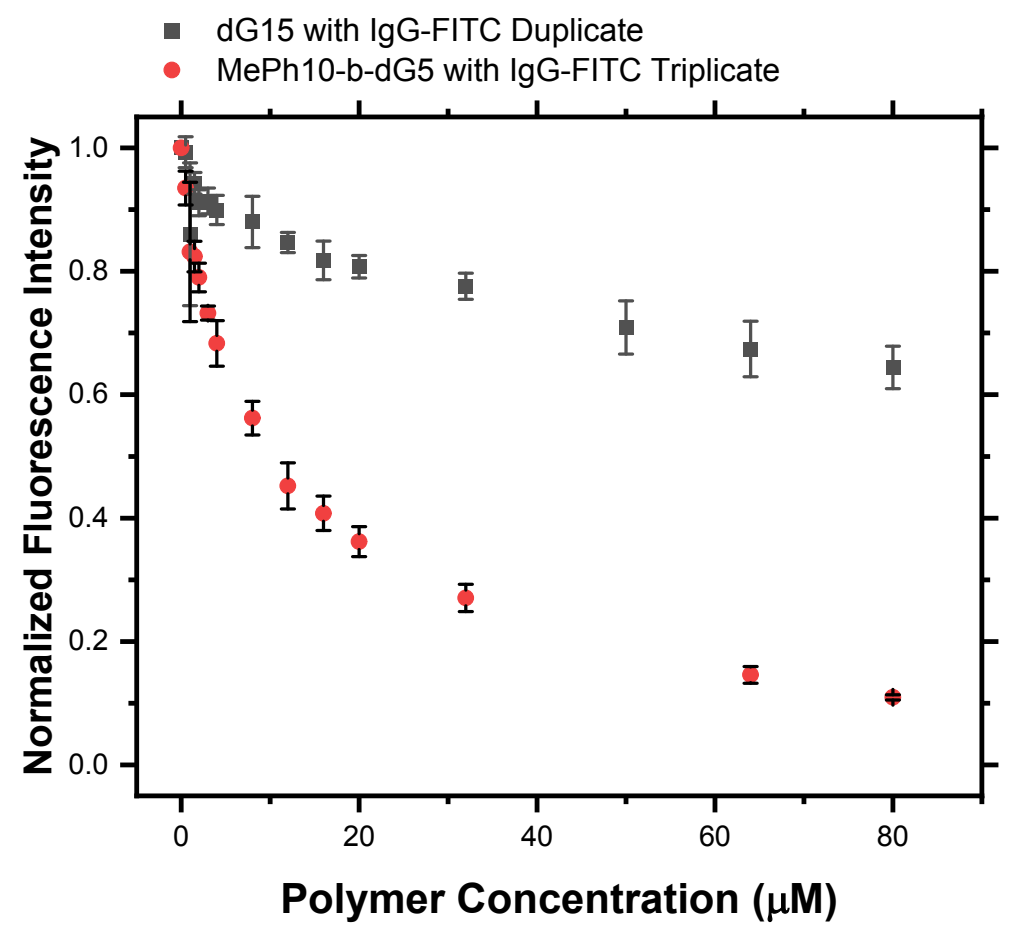

Figure S15: Comparison of $\mathbf{M e P h}_{\mathbf{1 0}}-\mathbf{b}-\mathbf{d G}_{\mathbf{5}}$ (red) and $\mathbf{d G}_{\mathbf{1 5}}$ (black) and IgG-FITC binding curves in 1x PBS. Data obtained from either two or three independent trials where error bars represent \pm one standard deviation.

\section{E. Binding Assays to Determine Salt Competition}

In order to probe the role of salt competition in polymer-protein binding, $\mathrm{RO}$ water was doped with increasing concentrations of sodium chloride and then added to a volume of 1x PBS to be used for binding experiments, loosely similar to the urea-containing experiments. The total well volume in the binding assay was $200 \mu \mathrm{L}$ per well and first for these salt competition experiments $150 \mu \mathrm{L}$ volume of BSA-FITC, polymer, and DMSO in 1x PBS was prepared and mixed. Next, $50 \mu \mathrm{L}$ of RO water doped with $\mathrm{NaCl}$ was added, and the final solution remixed. These solutions were prepared by weighing out $\sim 3.5 \mathrm{~g} \mathrm{NaCl}$ and dissolving in $\sim 10 \mathrm{~mL} \mathrm{RO}$ water (respectful of solubility of $\mathrm{NaCl}$ in water as $357 \mathrm{mg} / \mathrm{mL}$ ). Based on the final concentration of salt desired, the stock concentration was serially diluted and then added to the solution of 1x PBS containing protein, polymer, and DMSO. The final concentration of protein was $200 \mathrm{nM}$, final polymer concentration was $4 \mu \mathrm{M}$, and the total 
salt concentration (including original volume of 1x PBS) was $150 \mathrm{mM}, 500 \mathrm{mM}$, or $1500 \mathrm{mM}$, depending on the concentration of $\mathrm{NaCl}$ in $\mathrm{RO}$ water used. It should be noted that $\mathrm{PBS}$ does contain other salts, including potassium phosphate monobasic and sodium phosphate dibasic, but for simplicity only $\mathrm{NaCl}$ was used to dope $\mathrm{RO}$ water.

As a control, the fluorescence intensity of a polymer-protein complex created in a well of 50 $\mu \mathrm{L}$ of $\mathrm{RO}$ water doped with $\mathrm{NaCl}$ with $150 \mu \mathrm{L} 1 \mathrm{x}$ PBS (to yield a salt concentration of $150 \mathrm{mM}$ ) was compared to $200 \mu \mathrm{L}$ of $1 x$ PBS (which contains approximately $150 \mathrm{mM}$ salts), with no differences observed in fluorescence quenching. Lastly, all experiments contained controls with BSA-FITC in the $\mathrm{NaCl}$ and $\mathrm{RO}$ water and $1 \mathrm{x}$ PBS combination to serve as a positive control for every concentration of $\mathrm{NaCl}$ used. A corresponding negative control of DMSO in the $\mathrm{NaCl}$ and $\mathrm{RO}$ water and 1x PBS was designed for every concentration of $\mathrm{NaCl}$ used. $\mathrm{pH}$ of all solutions were carefully measured, but notably the addition of $\mathrm{RO}$ water with the highest salt concentration did slightly modify the $\mathrm{pH}$ resulting in a $\mathrm{pH}$ of $\sim 6.9$. Unless otherwise noted, salt-containing experiments were conducted in triplicate which included the weighing of $\mathrm{NaCl}$ and measurement of $\mathrm{pH}$.

\section{F. Binding Assays using Unlabeled BSA as a Competitor}

In order to test the role of unlabeled BSA as a competitor for polymer:protein binding, experiments were designed to first allow polymer:protein pairs to complex for thirty minutes, after which time a volume of concentrated BSA in 1x PBS would be added. Samples were then remixed, allowed to equilibrate for an additional thirty minutes, and then measured on the plate reader. A concentrated stock solution of BSA ( $\sim 100 \mathrm{~g} / \mathrm{L} \mathrm{BSA}$ in 1x PBS) was prepared and serially diluted to yield working stock solutions. Unlike previous binding experiments, the polymer and labelled protein concentrations were held constant in every well across the binding assay, and an increasing concentration of unlabelled BSA was added to each well. In every experiment a positive control of labelled protein (BSA-FITC or IgG-FITC) was measured, as well as a control of labelled protein 
with polymer and no additional BSA. Concentrations of BSA ranged from $200 \mathrm{nM}$ to $1000 \mu \mathrm{M}$. As this extensive range of BSA concentration introduced varying volumes of BSA to be added, an initial control was tested to ensure that adding this volume to the initial polymer:protein complex would not perturb binding. In this control, rather than adding a stock solution of BSA, only 1x PBS was added.

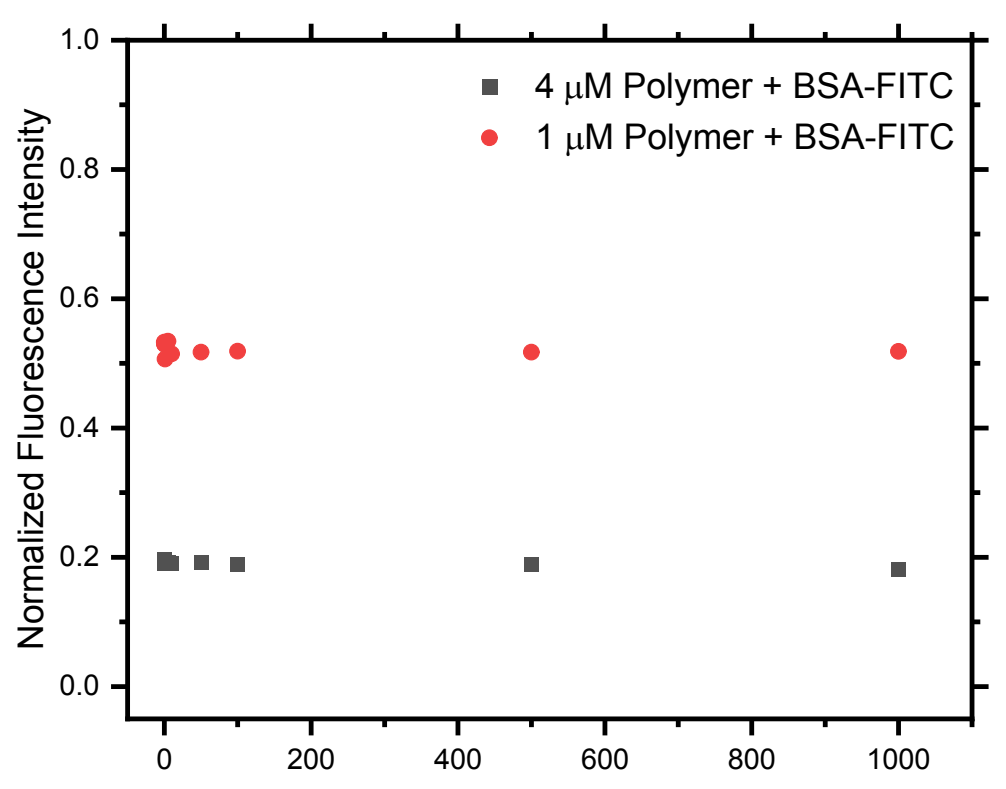

PBS Added to Match $[\mathrm{X}]$ BSA Concentration $(\mu \mathrm{M})$

Figure S16: Control experiment of polymer and BSA-FITC binding to ensure that additional volumes of unlabeled BSA would not perturb complexes, and corresponding volume of 1x PBS was added. Red points indicate concentration of $1 \mu \mathrm{M}$ polymer and black points indicate concentration of $4 \mu \mathrm{M}$ in every well. Results indicate no change is observed with the volume that the system would be diluted by in adding BSA.

As an additional control, as very high protein concentrations would be used, labelled proteins (BSAFITC and IgG-FITC) with only unlabeled BSA were measured to probe fluorescence quenching effects caused by BSA. At very high concentrations of BSA an effect can be observed on fluorescence quenching, and therefore for competitor experiments the fluorescence of polymer + labeled protein + unlabeled challenger is normalized against labeled protein + unlabeled challenger. 


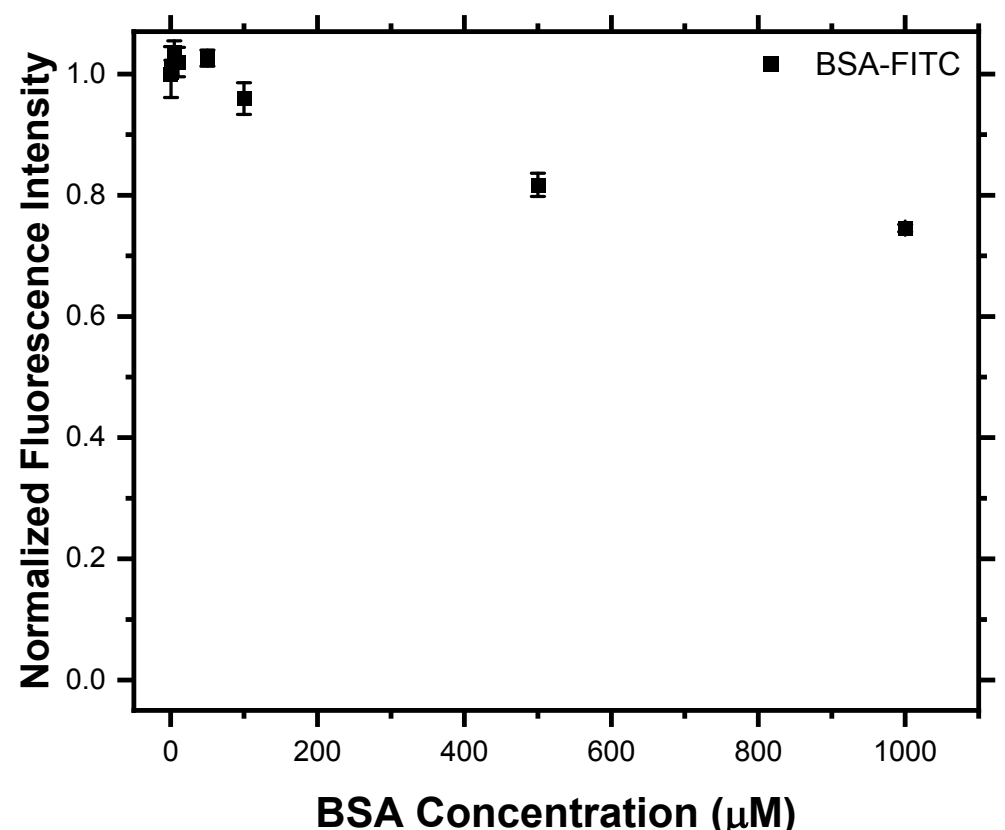

Figure S17: Control experiment of IgG-FITC quenching by unlabeled BSA at concentrations of 0 to $1000 \mu \mathrm{M}$. No wells contain polymer. Only two trials shown, error bars represent \pm one standard deviation.

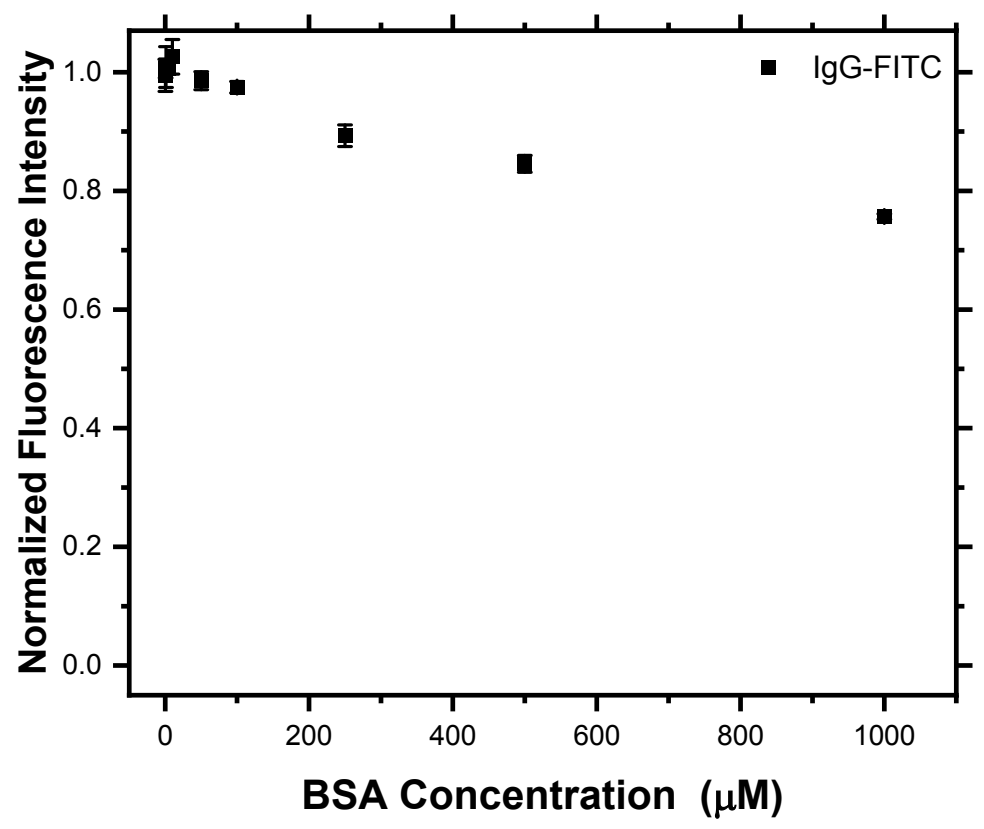

Figure S18: Control experiment of IgG-FITC quenching by unlabeled BSA at concentrations of 0 to $1000 \mu \mathrm{M}$. No wells contain polymer. Only two trials shown, error bars represent \pm one standard deviation. 


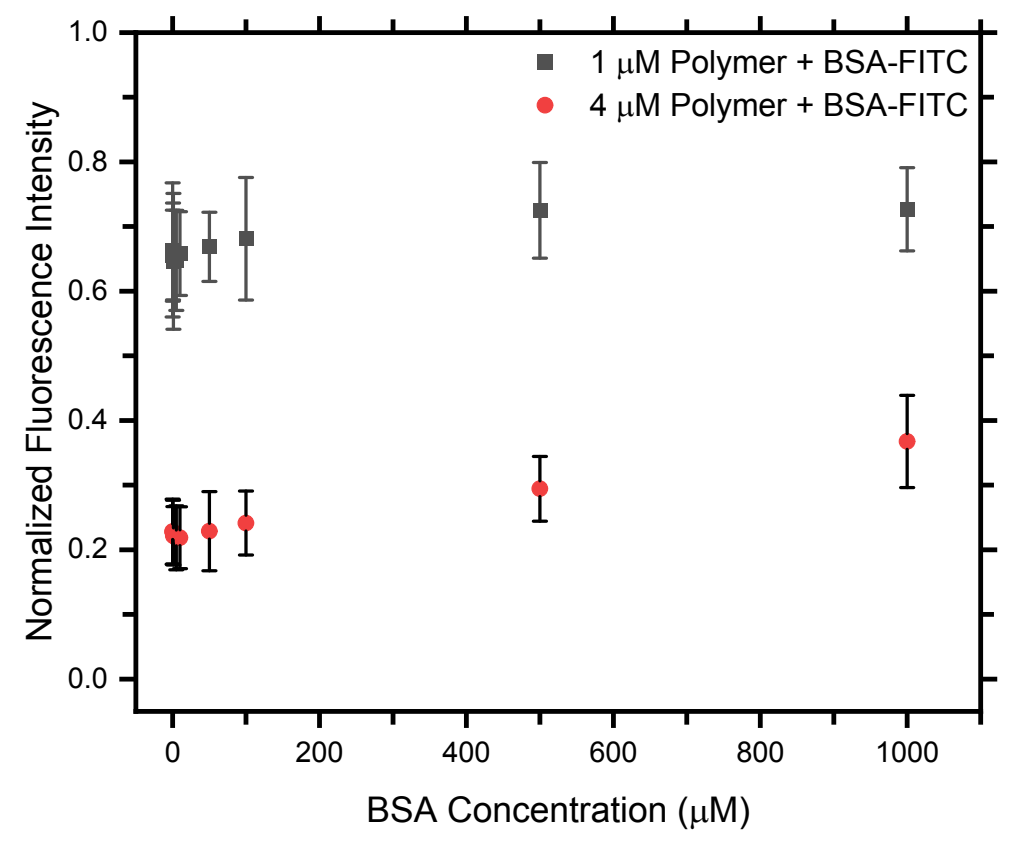

Figure S19. Competition assay for CPPM-BSA-FITC binding at two concentrations of $\mathbf{M e P h}_{\mathbf{1 0}} \mathbf{- b}-\mathbf{d G}_{\mathbf{5}}$, representing different positions of the initial binding curves measured in Figure 3A. The concentration of fluorescently labelled protein in all experiments was held constant at $200 \mathrm{nM}$. Fluorescence quenching competition experiments were conducted in triplicate and error bars represent $+/$ - one standard deviation. Values were normalized to the fluorescence intensity of labelled protein with each respective BSA concentration in the absence of polymer. 


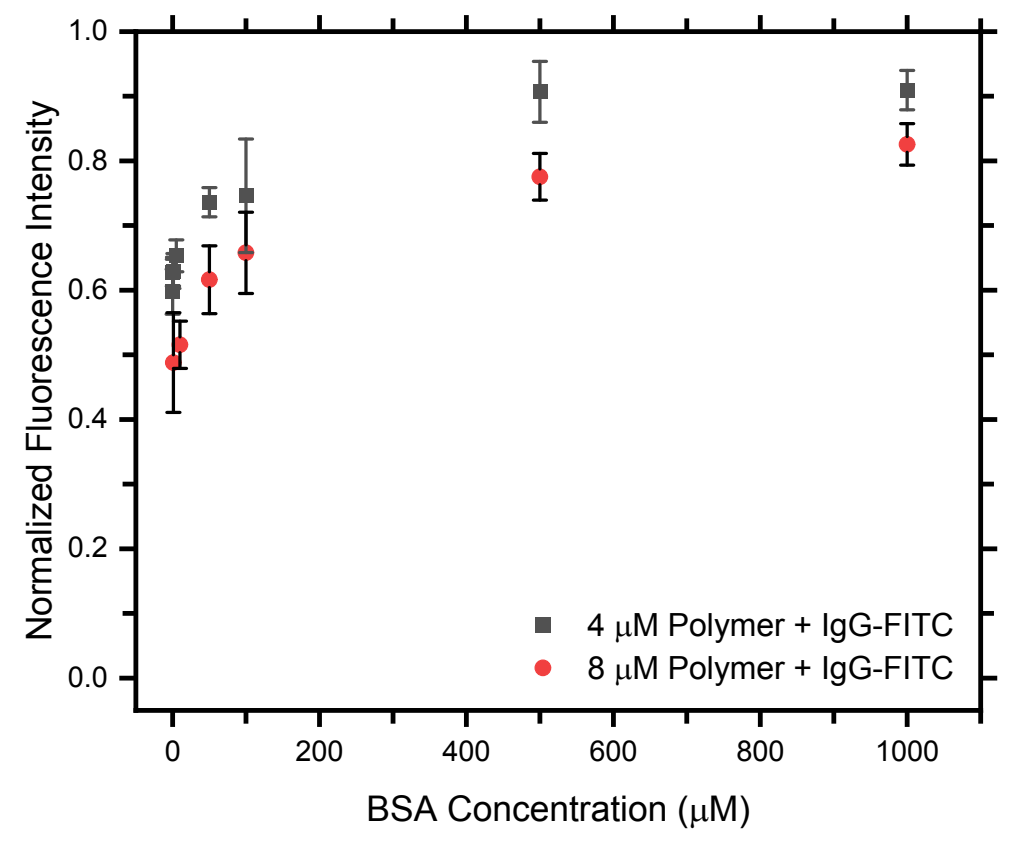

Figure S20: Competition assay for CPPM-IgG-FITC binding at two concentrations of $\mathbf{M e P h}_{\mathbf{1 0}}-\boldsymbol{b}-\mathbf{d G}_{\mathbf{5}}$, representing different positions of the initial binding curves measured in Figure S13. The concentration of fluorescently labelled protein in all experiments was held constant at $200 \mathrm{nM}$. Fluorescence quenching competition experiments were conducted in triplicate and error bars represent $+/$ - one standard deviation. Values were normalized to the fluorescence intensity of labelled protein with each respective BSA concentration in the absence of polymer. 


\section{References}

(1) Love, J. A.; Morgan, J. P.; Trnka, T. M.; Grubbs, R. H. A Practical and Highly Active RutheniumBased Catalyst That Effects the Cross Metathesis of Acrylonitrile. Angew. Chemie - Int. Ed. 2002, 41 (21), 4035-4037. https://doi.org/10.1002/1521-3773(20021104)41:21<4087::AIDANIE4087>3.0.CO;2-X.

(2) Lienkamp, K.; Madkour, A. E.; Musante, A.; Nelson, C. F.; Nüsslein, K.; Tew, G. N. Antimicrobial Polymers Prepared by ROMP with Unprecedented Selectivity: A Molecular Construction Kit Approach. J. Am. Chem. Soc. 2008, 130 (30), 9836-9843. https://doi.org/10.1021/ja801662y.

(3) DeRonde, B. M.; Torres, J. A.; Minter, L. M.; Tew, G. N. Development of Guanidinium-Rich Protein Mimics for Efficient SiRNA Delivery into Human T Cells. Biomacromolecules 2015, 16 (10), 3172-3179. https://doi.org/10.1021/acs.biomac.5b00795.

(4) Posey, N. D.; Hango, C. R.; Minter, L. M.; Tew, G. N. The Role of Cargo Binding Strength in Polymer-Mediated Intracellular Protein Delivery. Bioconjug. Chem. 2018, 29 (8), 2679-2690. https://doi.org/10.1021/acs.bioconjchem.8b00363. 